\title{
Experimental study of condensing steam flow in nozzles and linear blade cascade
}

Authors: $\quad$ Majkut M., Dykas S., Strozik M., Smolka K.

Affiliation: Institute of Power Engineering and Turbomachinery, Silesian University of Technology, Gliwice, Poland

Keywords: wet steam, condensation, experiment, numeric, nozzle, linear cascade

Summary:

Experimental investigations of non-equilibrium spontaneous condensation in transonic steam flow were carried out in nozzles and linear blade cascade. For the tests the geometry of the half arc nozzles were used. The linear cascade consists of the stator blades of the last stage low pressure steam turbine. The applied experimental test section is a part of small scale steam power station located at the Silesian University of Technology. The steam parameters at the test section inlet correspond to the real conditions in low pressure part of steam turbine. The applied linear cascade consists of four stator blades of the last LP stage, it means that the flow through three full blade-to-blade channels were investigated. The information about the flow-filed were acquired by means of static pressure measurements on the pressure and suction side of the one bladeto-blade channel and with the use of Schlieren technique. The static pressure measurements on the blades surfaces were synchronized with the measured total parameters at the inlet and also with the Schlieren pictures, with the frequency of $100 \mathrm{~Hz}$. The tests were performed for the wide range of the outlet Mach number $(\mathrm{Ma}=0.8-1.4)$.

The capabilities of used measurement techniques were estimated for gaining insight into condensation process in steam flow. The experimental results were compared with numerical calculations carried out by means of an in-house CFD code. 